\title{
Trend analysis of wave storminess: wave direction and its impact on harbour agitation
}

\author{
M. Casas-Prat and J. P. Sierra \\ Centre Internacional d'Investigació dels Recursos Costaners, Jordi Girona 1-3, Mòdul D1 Campus Nord, \\ 08034 Barcelona, Spain \\ Laboratori d'Enginyeria Marítima, Universitat Politècnica de Catalunya, Jordi Girona 1-3, Mòdul D1 Campus Nord, \\ 08034 Barcelona, Spain
}

Received: 7 June 2010 - Revised: 13 October 2010 - Accepted: 21 October 2010 - Published: 19 November 2010

\begin{abstract}
In the context of wave climate variability, longterm alterations in the wave storminess pattern of the Catalan coast (northwestern Mediterranean Sea) are analysed in terms of wave energy content and wave direction, on the basis of wave hindcast data (from 44-year time series). In general, no significant temporal trends are found for annual mean and maximum energy. However, the same analysis carried out separately for different wave directions reveals a remarkable increase in the storm energy of events from the south, which is partly due to a rise in the annual percentage of such storms. A case study of Tarragona Port (on the southern Catalan coast) highlights the importance of including changes in wave direction in the study of potential impacts of climate change. In particular, an increase in the frequency of storms from the south leads to greater agitation inside the Port.
\end{abstract}

\section{Introduction}

Climate change is an important area of current scientific research because of potential future hazards. The greenhouse effect is expected to lead to global warming. The resulting complex interactions in atmospheric processes may cause substantial modifications in near-surface wind and pressure patterns. This could affect typical mean and extreme wave conditions, leading to variations in coastal hydrodynamics. Stormy conditions are especially important because they are closely related to more hazardous events, including extremely high water levels that may be one of the main causes of extensive property damage in coastal areas (De Zolt

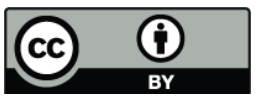

Correspondence to: M. Casas-Prat (merce.casas@upc.edu) et al., 2006; Soomere et al., 2008). Weisse and von Storch (2010) give a general overview of the state-of-theart in the relation between anthropogenic climate change and marine climate. Processes such as changing temperature gradients, increasing amount of water vapour and variations in sea surface temperatures might modify the number, frequency and situation of mid-latitude $\left(30^{\circ}-60^{\circ}\right)$ storm tracks. However, due to incomplete understanding of the system and computer limitations, a wide range of possible changes have been described in the literature and some of them (especially in the case of regional projections) are still being disputed.

In addition, a high inter-annual and decadal variability in sea levels and wave patterns has been detected in the Mediterranean Sea for the second half of the 20th century (Musić and Nicković, 2008; Ratsimandresy et al., 2008b; Tsimplis et al., 2008) and could have an impact on coastal areas that is as great as that of climate change.

This study focuses on the Catalan coast (northwestern Mediterranean Sea), as shown in Fig. 1, and aims to identify and quantify possible trends in storm wave-related parameters. It is an extension of a previous study carried out by Casas-Prat and Sierra (2010) and is based on hindcast data covering the second half of the 20th century. Due to the nature of these data, some limitations may prevent us from properly detecting the real long-term variability. However, the use of this database is justified because, unlike wave measurements, it comprises a consistent data series that is long enough for climate studies ( $>40$ years).

We aim to increase knowledge of long-term variations in wave storminess in this semi-enclosed sea domain, in which the wave climate is complex and was defined as "torrential" by Sánchez-Arcilla et al. (2008). Although some strong events are controlled by larger-scale synoptic activity, local

Published by Copernicus Publications on behalf of the European Geosciences Union. 


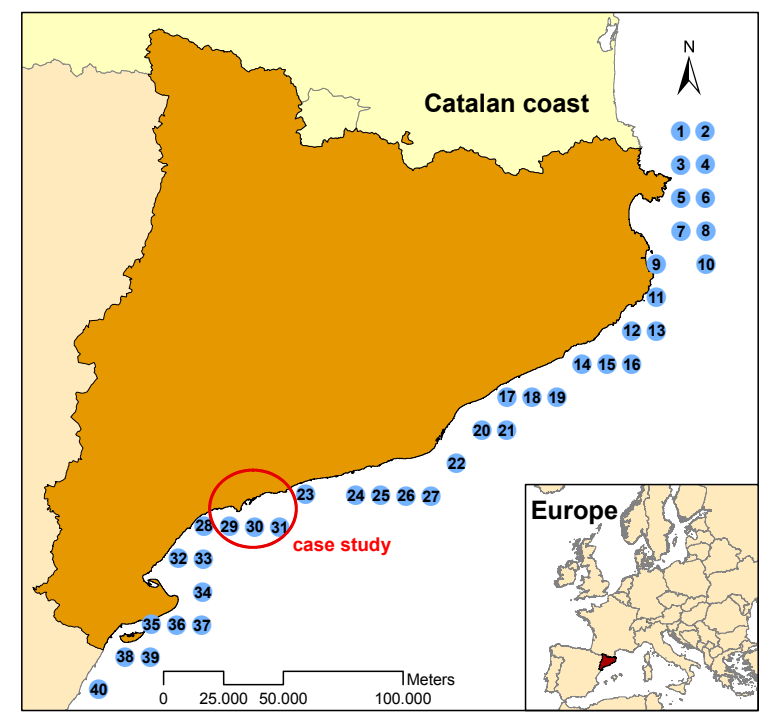

Fig. 1. Location of the Catalan coast and simulated nodes considered in this study.

topography has a significant impact on the wind climate and therefore on the wave field (Bertotti and Cavaleri, 2008). Waves are further modified by the irregular bathymetry of the zone (Sánchez-Arcilla et al., 2008). Hence, regional temporal trends may differ from the results of more general studies.

In this paper, special emphasis is placed on wave direction, an important factor that has been underestimated or simply ignored in previous studies of the area. Even in a situation of constant wave storminess magnitude, rotation of the mean wave direction may have severe consequences, since most beach and harbour defence structures are designed assuming a permanent directional distribution of waves. Liste et al. (2004) illustrated this fact with an example in which a rotation of only 2 degrees in the mean energy flux vector could produce a beach retreat of $20 \mathrm{~m}$. A higher frequency of coastal storms in the same direction as the harbour mouth would influence port operations, as it could cause increased agitation and siltation. Since most Catalan ports and marinas are oriented to the south, they are extremely vulnerable to an increase in extreme events from this direction. The present study illustrates this possible impact by computing and comparing harbour agitation in current and future situations in a case study of Tarragona Port (see Fig. 1).

\section{Data}

In spite of the obvious advantages of in situ measurements, they are usually limited in spatial and temporal coverage. Temporal coverage is crucial in long-term analysis. In addition, in situ measurements are usually inhomogeneous, as their accuracy increases over time, which is not suitable for climate studies. Therefore, the present analysis is based on simulations: 44-year hindcast wave data (1958-2001) from the European HIPOCAS project (Guedes Soares et al., 2002). This simulated data set is available for several European coastal areas, including the entire Mediterranean basin. It used REMO, the regional atmospheric model, which was forced with NCEP and followed by the HAMSOM and WAM (WAMDI, 1988; Monbaliu et al., 2000) models to simulate the sea level and wave data, respectively. The HIPOCAS database is widely used (Gomis et al., 2008; Marcos and Tsimplis, 2008; Tsimplis, et al., 2008; Alvarez-Ellacuria et al., 2009; Mösso et al., 2009) and has been extensively validated for wind speed and direction, significant wave height, wave direction and residual sea level parameters in the Mediterranean Sea (Sotillo et al., 2005; Musiv and Nicković, 2008; Ratsimandresy et al., 2008a, b). Although some extreme events are underestimated, this database seems to be useful in the study of the long-term behaviour of these parameters. A calibrated data set has been computed to try to diminish the negative bias (Tomás et al., 2004). It was obtained by minimising the distance between the probability distributions of measurements and simulations, through the application of an exponential relation. In our study area, few storms are better captured by this calibrated sample. However, most of the observations are systematically overpredicted, as shown in the example in Fig. 2 (Tortosa buoy, 1993) that compares the absolute error of the two data sets for a certain location and time period. In general, the figure illustrates that the calibrated HIPOCAS data nearly always overestimate the buoy measurements, whereas an average error that is closer to zero is found for the uncalibrated data. In addition, larger differences (up to $2.83 \mathrm{~m}$ ) are found for the calibrated data than for the uncalibrated data (up to $1.75 \mathrm{~m}$ ). Figure 3 shows the mean ratio between the relative errors, in absolute value, of calibrated and uncalibrated data sets. This plot was obtained by comparing the hindcast data with buoy measurements at the same location as in Fig. 2, but considering the time period 1991-2001. The error ratio was computed for subsets of data with significant wave heights $\left(H_{\mathrm{s}}\right)$ above a certain value. For example, for $x=3 \mathrm{~m}$, we find $y=1.3 \mathrm{~m}$. This means that, on average, the relative error of calibrated data is 1.3 times that of uncalibrated data for all $H_{\mathrm{s}}>3 \mathrm{~m}$. Generally, this ratio is higher than 1 (in favour of uncalibrated data), particularly for all wave heights $\left(H_{\mathrm{s}}>0 \mathrm{~m}\right)$ and for extreme wave heights $\left(H_{\mathrm{s}}>3 \mathrm{~m}\right)$. Therefore, the original data set is used in this study because it performs better. Figure 1 illustrates the 40 selected nodes along the Catalan coast from which the significant wave height $\left(H_{\mathrm{s}}\right)$ and the mean wave direction $(\theta)$ were considered. The spatial resolution was about $12.5 \mathrm{~km}$ and the time step was $3 \mathrm{~h}$. 


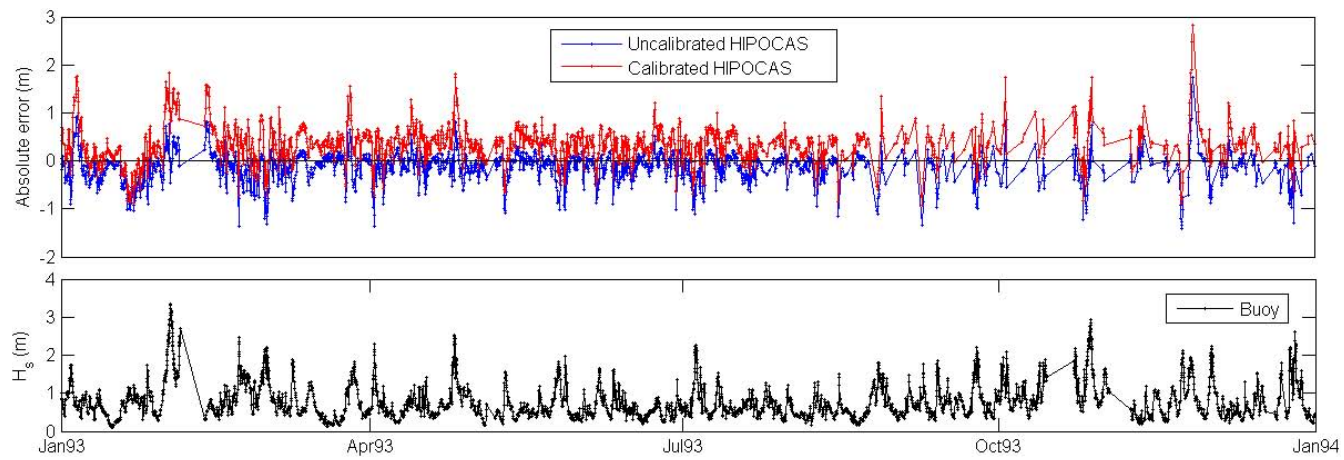

Fig. 2. Upper panel: differences between hindcast (calibrated and uncalibrated) data and buoy measurements during 1993 in Tortosa. Lower panel: $H_{\mathrm{S}}$ buoy time series (Tortosa buoy coordinates: $40^{\circ} 43.29^{\prime} \mathrm{N}, 00^{\circ} 58.89^{\prime} \mathrm{E}$, from XIOM network).

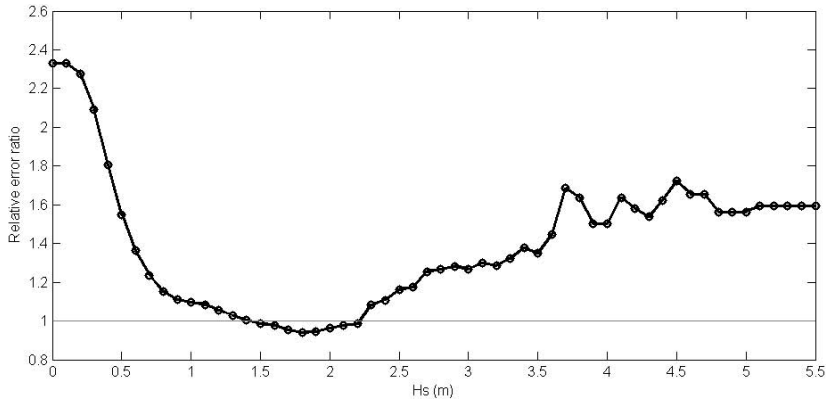

Fig. 3. Mean ratio between relative errors of calibrated and uncalibrated HIPOCAS data for subsets of time series of $H_{S}$ greater than the values of $\mathrm{x}$-axis (for the time period 1991-2001 from Tortosa buoy: $40^{\circ} 43.29^{\prime} \mathrm{N}, 00^{\circ} 28.89^{\prime} \mathrm{E}$ ).

\section{Methods}

The methods are explained below in five subsections, in which the following aspects are covered:

1. Wave storminess characterisation: storm energy content and directional frequency.

2. Trend analysis of storm energy content.

3. Trend analysis of wave directional frequency.

4. Application to the case study.

5. The role of uncertainty.

\subsection{Wave storminess characterisation}

As the present analysis focuses on extreme conditions, first we must define a wave storm. The common peak over threshold (POT) method is used with a typical $H_{\mathrm{s}}$ threshold of $2 \mathrm{~m}$ (within the range of values recommended by the Spanish National Harbour Authority) and a minimum duration of $6 \mathrm{~h}$. Additionally, a second hypothesis is formed in which only statistically independent storms are considered (Mendoza and Jiménez, 2006). In this case, a storm involving two extreme episodes with a maximum inter-event separation of $72 \mathrm{~h}$ and a period of wave heights under $1.5 \mathrm{~m}$ in less than $6 \mathrm{~h}$ is considered a single two-peaked storm.

To characterise wave storminess for each storm, we use the storm energy content $\left(E_{\mathrm{s}}\right)$ which combines both $H_{\mathrm{s}}$ and duration as the integral over time illustrated in Eq. (1) (Mendoza and Jiménez, 2004). In addition, wave storminess is classified depending on the incoming wave direction of the storm peak, according to the following eight sectors of $45^{\circ}$, which are centred in the four cardinal and four ordinal directions of a compass rose: north $(\mathrm{N})$, northeast (NE), east (E), southeast (SE), south $(\mathrm{S})$, southwest (SW), west (W), northwest (NW).

$E_{\mathrm{s}}=\int H_{\mathrm{s}}^{2} d t$

To evaluate long-term trends rather than seasonal variability, the annual mean and maximum values of $E_{\mathrm{s}}$ are calculated for each sector and for all the storms in each year. Moreover, the same operation is carried out for the entire period of data (1958-2001) to obtain a general picture of the past-present situation and to identify the most energetic locations and directions. In addition, for the entire period of data as well, the circular correlation (Fisher and Lee, 1983; see Eq. 2) between wind and wave directions in stormy conditions is computed to gain an idea of the presence of sea and swell in each node.

$$
r=\frac{\sum_{i=1}^{n-1} \sum_{j=i+1}^{n} \sin \left(\theta_{i}-\theta_{j}\right) \sin \left(\alpha_{i}-\alpha_{j}\right)}{\sqrt{\sum_{i=1}^{n-1} \sum_{j=i+1}^{n} \sin ^{2}\left(\theta_{i}-\theta_{j}\right) \sum_{i=1}^{n-1} \sum_{j=i+1}^{n} \sin ^{2}\left(\alpha_{i}-\alpha_{j}\right)}}
$$

where $n$ is the number of data items, $\theta$ the wave direction and $\alpha$ the wind direction. The aim of this classification is not to make a clear distinction between these two phenomena, but to illustrate the type of wave climate to which significant temporal changes are most closely related. 
The second parameter used to characterise the wave storminess is the directional frequency in stormy conditions, in other words, the percentage of storms associated with each direction in a certain year. Casas-Prat and Sierra (2010) calculated these annual frequencies by Bayesian inference (Agresti, 2002; see Eq. 3), from which $p_{i} \neq 0$ because $p_{i} \geq 0.5 \cdot\left(n_{\text {total }}+0.5 k\right)^{-1}$. This property is useful in both theoretical and practical terms. Firstly, although the occurrence of a storm from a certain direction may be highly unlikely (e.g. offshore directions) and may not in fact have been simulated during the entire period, zero probability should not be assigned, as this means the negation of such an event. Secondly, as shown in Sect. 3.3, compositional data is log-ratio transformed, which results in the exclusion of zeros. However, when $n_{\text {total }}$ is relatively small (a few annual storms), the probability of an absent event is exaggeratedly increased by using Eq. (3), which in turn is compensated by considerably lowering the value of higher percentages. This might cause some distortion in the results.

$p_{i}=\frac{n_{i}+0.5}{n_{\text {total }}+0.5 k}$, for $i=1, \ldots, k$

where $n_{i}$ and $n_{\text {total }}$ are, respectively, the number of storms per sector and in total, and $k=8$ is the number of classes.

To overcome the aforementioned disadvantage, we obtain the frequencies directly by computing $p_{i}^{*}=n_{i} / n_{\text {total }}$. Then, a multiplicative replacement strategy is applied to the zeros of the compositional data set (Martín-Fernández et al., 2003; see Eq. 4). In principle, Eq. (4) is defined for use with rounded zeros. However, owing to the theoretical and practical reasons explained above, this expression is extrapolated to this case of absolute zeros.

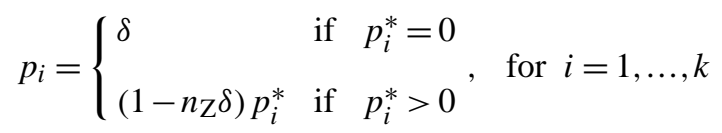

where $n_{Z}$ is the number of zeros and $\delta$ the imputed value for zeros $(\delta=0.01)$. As in the energy analysis, the frequencies for the entire period of data (1958-2001) are also calculated.

\subsection{Trend analysis of storm energy content}

Before the trend analysis, an adjustment should be made according to the data scale, since most standard techniques are designed to be used with data that are free to range from $-\infty$ to $\infty$. By definition, $E_{\mathrm{s}}$ is generally a positive variable and therefore its scale is relative. Therefore, $E_{\mathrm{s}}$ is $\log$-transformed so that distorted distances are not measured when linear regression analysis (which assumes normally distributed data) is performed, for example. Note that this positive assumption is subject to the annual presence of storms. In situations in which most of the years have storms (e.g. when all directions are considered), one year without storms is associated with a very low energy threshold value, to avoid the problem of $\ln (0)$. However, when there are many years without storms (e.g. for the S direction) the probability of storm occurrence is introduced (see below in the trend quantification procedure).

A two-step method is used for the trend analysis of storm energy content: trend detection and trend quantification. As in Casas-Prat and Sierra (2010), the Mann-Kendall (MK) test (Mann, 1945; Kendall, 1975; see Eqs. 5, 6, 7 and 8) is performed for the trend detection for all the calculated annual mean and maximum time series of $E_{\mathrm{s}}$, to detect the locations and directions in which major long-term changes can be expected in terms of energy. This nonparametric test is recommended by van Gelder et al. (2008) as it is less sensitive to outliers and does not assume any trend shape. This is a rank-based test that measures the strength of the monotonic relationship between two variables. Under the null hypothesis of no trend with a time series $\left\{x_{1}, x_{2}, \ldots, x_{N}\right\}$ from a population in which the random variables are independent and identically distributed, the MK test uses the $z$ statistic, which is standard normally distributed:

$z=\left\{\begin{array}{lll}(S-1) / \sigma_{S} & \text { if } & S>0 \\ 0 & \text { if } & S=0 \\ (S+1) / \sigma_{S} & \text { if } & S<0\end{array}\right\} \sim N(0,1)$

where $S$ is calculated as follows:

$S=\sum_{i=1}^{N-1} \sum_{j=i+1}^{N} \operatorname{sgn}\left(x_{j}-x_{i}\right)$

in which $\operatorname{sgn}(x)$ is the sign function. The variance of $S, \sigma_{S}^{2}$ is calculated by Eq. (7), which accounts for the possibility of equal $x$ values:

$\sigma_{S}^{2}=\frac{1}{18}\left[N(N-1)(2 N+5)-\sum_{i=1}^{m} t_{i}\left(t_{i}-1\right)\left(2 t_{i}+5\right)\right]$

where $m$ is the number of tied groups in the data set and $t_{i}$ the number of data points in the $i$-th tied group. Regarding the basic assumption of independence of the MK test, von Storch (1995) noted that positive serial correlation in time increases the possibility of rejecting the null hypothesis of no trend. However, the annual time series of $E_{\mathrm{S}}$ can be assumed to be independent. The significance level used to perform the statistical test (see Eq. 8) is $\alpha_{\mathrm{MK}}=0.1$, which is slightly higher than the typical value of 0.05 so as not to miss any possible trends in the second step of the analysis.

if $\begin{cases}z>\phi^{-1}\left(1-\alpha_{\mathrm{MK}} / 2\right) & \Rightarrow \text { Positive trend } \\ z<\left|\phi^{-1}\left(1-\alpha_{\mathrm{MK}} / 2\right)\right| & \Rightarrow \text { No trend } \\ z<-\phi^{-1}\left(1-\alpha_{\mathrm{MK}} / 2\right) & \Rightarrow \text { Negative trend }\end{cases}$

in which $\phi^{-1}(\cdot)$ is the inverse of the standard normal cumulative density function. 
Secondly, in the trend quantification for interesting nodes with a previously detected trend, a classical linear regression analysis is carried out and complemented with the bootstrap technique (Efron, 1979) using 1000 simulated samples to capture the uncertainty in the temporal trend. Linear regression analysis is performed for $\ln \left(E_{\mathrm{s}}\right)$, and therefore the relationship between $E_{\mathrm{s}}$ and time becomes exponential. As stated above, for wave directions that have had no storms for several years, the probability of storm occurrence $\left(p_{\mathrm{s}}\right)$ is introduced and the low energy threshold replacement strategy is not used, since its use and abuse may distort the results. In such cases, the values of $E_{\mathrm{s}}$ for years without storms are simply removed and the temporal trend of $E_{\mathrm{s}}$, which is now conditioned to storm occurrence, is calculated by linear regression as explained above (to avoid the "zero" problem). Two coefficients are obtained for each node: $a_{E}$ and $b_{E}$. Separately, the temporal trend of $p_{\mathrm{s}}$ is obtained by binomial logistic regression and, finally, the product of these two trends is the approximation of the temporal evolution of $E_{\mathrm{S}}$ (see Eq. 9). The same bootstrapping method is used to assess the uncertainty.

$$
E_{\mathrm{S}}(t)=p_{\mathrm{s}}(t) \cdot \exp \left(a_{E} t+b_{E}\right)
$$

\subsection{Trend analysis of wave directional frequency}

Wave directional frequencies are compositional data and require previous conversion, as there is a link between proportions (they are defined in the simplex space). If the data were not converted, the results of regression analysis, for instance, would be clouded by spurious effects (PawlowskyGlahn and Egozcue, 2006). The isometric log-ratio (ilr) transformation (Egozcue et al., 2003; see Eq. 10) is one of the best alternatives as it preserves the isometry. This transformation translates the $k=8$ directional percentages $\left\{p_{1}, \ldots, p_{8}\right\}$ into 7 coordinates $\left\{y_{1}, \ldots, y_{7}\right\}$ on an orthonormal basis in a real vector space $\Re^{7}$, obtained from sequential binary partition $\left(R_{i}, S_{i}\right)$. The conversion can be expressed as the log-ratio between the geometric mean of each partition $\left(g\left(p_{\in R_{i}}\right), g\left(p_{\in S_{i}}\right)\right)$, multiplied by a normalising factor $a\left(r_{i}, s_{i}\right)$.

$y_{i}=a\left(r_{i}, s_{i}\right) \ln \left(\frac{g\left(p_{\in R_{i}}\right)}{g\left(p_{\in S_{i}}\right)}\right), \quad a\left(r_{i}, s_{i}\right)=\sqrt{\frac{r_{i} s_{i}}{r_{i}+s_{i}}}$,

for $i=1, \ldots, k-1$

where $r_{i}$ and $s_{i}$ are the number of elements in each partition. After some basic algebraic transformations, this expression can be rewritten as Eq. (11) for a certain year $t$ :

$\boldsymbol{y}(t)=\mathbf{M} \cdot \ln (\boldsymbol{p}(t))$

where $\boldsymbol{y}=\left[y_{1}, \ldots, y_{7}\right]^{T}, \boldsymbol{p}=\left[p_{1}, \ldots, p_{8}\right]^{T}$ and $\mathbf{M}$ is a certain matrix of known coefficients of $7 \times 8$ dimensions. The partition that is used is, in principle, arbitrary, especially if we are more interested in the final result in terms of the original percentages than in the interpretation of the coordinates obtained by the transformation.

Once the original values have been transformed for each year, we perform a classical linear regression analysis complemented with bootstrapping, which is similar to the storm energy content case explained in the previous subsection. Thus, we obtain a linear relation between the 7 coordinates and time, defined by two vectors of coefficients: $\boldsymbol{a}$ and $\boldsymbol{b}$. To obtain the expected $\left\{\hat{p}_{1}, \ldots, \hat{p}_{8}\right\}$ values (or 95\% confidence intervals) for a certain time, the inversion conversion is carried out (Eq. 12).

$$
\hat{\boldsymbol{p}}(t)=C \exp \left(\mathbf{M}^{T} \cdot(\boldsymbol{a} t+\boldsymbol{b})\right)
$$

in which $C$ is the closure operation to fit the relationship $\sum_{i=1}^{8} \hat{p}_{i}=1$. To better interpret and discuss the results, instead of using the coefficients $\boldsymbol{a}$ and $\boldsymbol{b}$ from the complex expression of Eq. (12), two extrapolations are calculated: 2010 (for the present) and 2050 (for the future). In turn, these are used for the application study on harbour agitation (see Sect. 3.4). The extrapolation is performed as follows: the linear trends ( $\boldsymbol{a}$ and $\boldsymbol{b})$ are used to calculate the extrapolated values $\boldsymbol{y}(t=2010)$ and $\boldsymbol{y}(t=2050)$. Subsequently, the inverse conversion (see Eq. 12) is performed to obtain $\hat{\boldsymbol{p}}(t=2010)$ and $\hat{\boldsymbol{p}}(t=2050$ ). These projected percentages (and their 95\% marginal confidence intervals) are named "projections". However, we must bear in mind the limitations of the methods, due to the underlying assumptions and the hindcast data that are used.

\subsection{Harbour agitation modelling}

A number of numerical models simulate wave propagation inside a harbour. These include Boussinesq-type models, which have been widely used as they can reproduce most of the physical processes involved in wave propagation. Boussinesq-type models (Peregrine, 1967) were originally developed to simulate the propagation of long waves. Various subsequent modifications (Sierra et al., 1988; Madsen et al., 1991; Nwogu, 1993; Chen and Liu, 1995) enabled these models to solve wind-wave propagation and low-frequency motion. Mutual interactions between short and long waves are inherent in these models. Therefore, they enable the study of nonlinear processes involved in the propagation, breaking and run-up of irregular wave trains (Karambas and Koutitas, 2004).

There are numerous examples of the application of such models to harbour agitation. Bingham (2000) used a Boussinesq model to predict the induced short- and longwave motion of a restrained floating body in restricted water. Nadaoka and Raveenthiran (2002) developed a phaseaveraged Boussinesq model to describe wave groups and the accompanying long-wave evolution. Karambas and 
Koutitas (2004) employed a Boussinesq model to simulate low-frequency waves induced by short-wave groups. They found good agreement between their calculations and experimental data taken from the literature. Woo and Liu (2004) developed a finite element model for modified Boussinesq equations and applied it to the study of harbour resonance problems. González-Marco et al. (2008) used a Boussinesq-type model to analyse the propagation of short and long waves inside a Spanish harbour and their effect on port operations.

In this paper, a Boussinesq-type model (González-Marco et al., 2008) is applied to a harbour on the Catalan coast to illustrate the impact on harbour agitation of potential changes in wave storm direction. We study Tarragona Port, which is one of the most active in the Mediterranean area in terms of cargo (33.3 million tons per year) and vessel traffic (2700 arrivals per year) (Mestres et al., 2010). The port is located on the southern Catalan coast $\left(41^{\circ} 0.5^{\prime} \mathrm{N} ; 1^{\circ} 14^{\prime} \mathrm{E}\right)$. It is about $4.5 \mathrm{~km}$ long and $2 \mathrm{~km}$ wide and lies along a longitudinal axis with an approximate NE-SW orientation.

The following procedure is used to assess the potential changes in Tarragona port agitation. Wave propagation inside the harbour is simulated for the different possible directions entering the port and an average agitation coefficient (the ratio between the wave height at a point and the incident wave height) is computed for the entire harbour and for each direction. Taking into account the frequency of each of these directions in the present and future conditions (2010 and 2050 projections, see Sect. 3.3) according to the estimated trends, an overall agitation coefficient can be computed that considers all directions. This coefficient is subjected to the assumptions and used to assess expected temporal variations in agitation under storm conditions. To evaluate part of the uncertainty of these results (see Sect. 3.5), the $95 \%$ confidence intervals of these overall agitation coefficients are calculated using the bootstrap technique. In other words, for each time scenario (2010 and 2050), 1000 samples of the eight-directional percentages are obtained. For each sample, the agitation coefficient is calculated by considering only the directions that produce waves that affect the harbour (the other directions lead to null agitation). Finally, the quantiles of the obtained sample of overall agitation coefficients establish the confidence band that integrates the uncertainty between directions.

\subsection{The role of uncertainty}

A correct assessment of uncertainty is crucial in a longterm analysis, especially in the context of wave climate variability. In this study, we only consider the uncertainty associated with the inherent variability of the data. The bootstrap technique is used to bound the results, as explained frequently in different processes of trend quantification. In general, 1000 samples are simulated for each case to compute robust $95 \%$ confidence intervals as their quantiles,

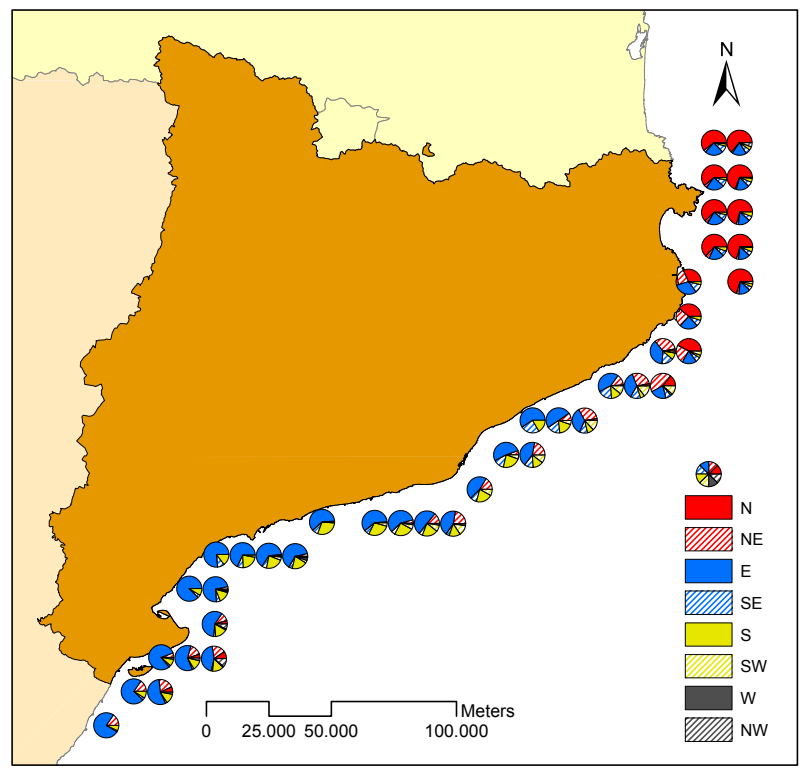

Fig. 4. Mean frequency for each direction for the data period 19582001 (sector areas proportional to the percentages).

as a function of time or for a certain projection. Despite its simplicity, bootstrapping, which is computer intensive, has been proven to be a suitable method for this type of analysis, in combination with linear regression. Casas-Prat and Sierra (2010) compared the uncertainties thus obtained with a Bayesian model (with flat priors) and the results were very similar. This suggests that, in a general case with little a priori information, the combination of linear regression + bootstrapping is more suitable than the more complex Bayesian method. Nevertheless, if more prior knowledge were available, a Bayesian analysis with more informative priors might reduce the uncertainty.

Other sources of uncertainty, which are very difficult to quantify, are not accounted for in the present study and, therefore, the confidence bands represent a lower boundary of the total uncertainty. Two examples of such uncertainty are the intrinsic errors present in the data due to the modelling (as discussed in Sect. 2) or the chosen model for trend extrapolation, which is related to the evolution of the atmospheric patterns.

\section{Results and discussion}

\subsection{Wave storminess characterisation}

To characterise wave storminess for the second half of the 20 th century, in this subsection we present the storm energy content $\left(E_{\mathrm{S}}\right)$ and directional frequency $\left(p_{i}\right)$ results for the entire data period of data (1958-2001). Figure 4 shows $p_{i}$ as a pie chart for each location, in which the surface areas are proportional to the percentages. Figure 5 illustrates the mean and maximum values of $E_{\mathrm{s}}$ for each direction and location. 

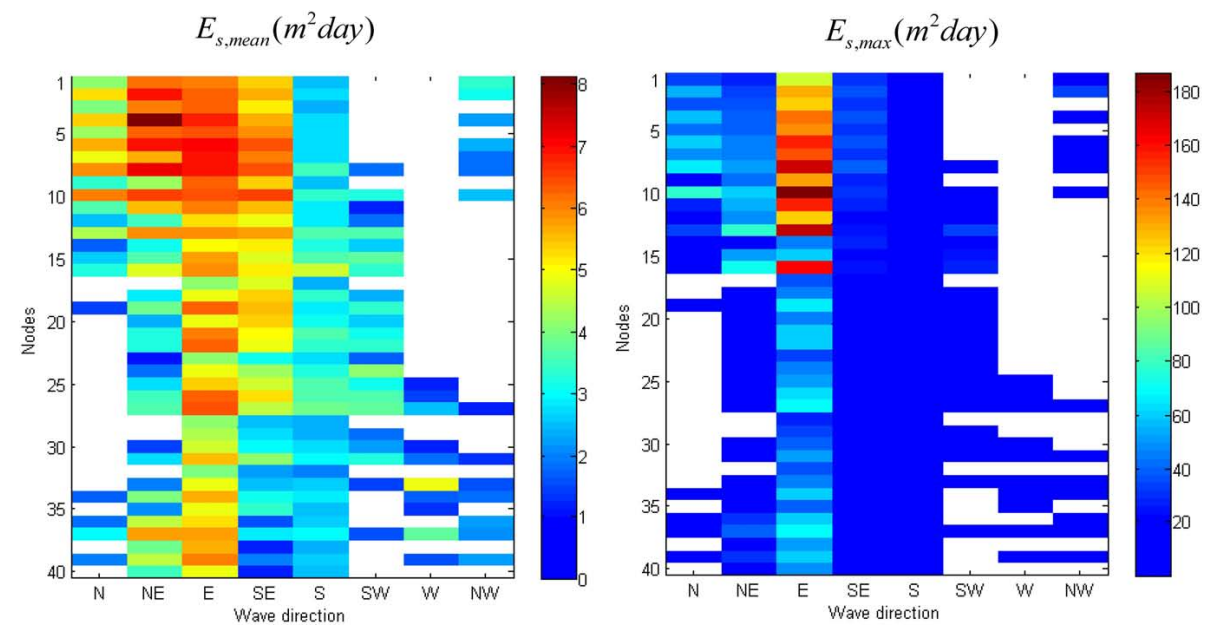

Fig. 5. Mean and maximum $E_{\mathrm{S}}$ for each direction and each node along the Catalan coast.

In terms of both frequency and intensity, the Catalan coast is clearly dominated by storm events coming from the $\mathrm{E}$ (see Figs. 4 and 5), in which larger fetches and stronger winds coincide (Sánchez-Arcilla et al., 2008). N events are the most frequent on the northern Catalan coast, although the maximum storm energy content is again associated with the E direction (see Figs. 4 and 5). S and SE events are generally remarkable, even though they are less intense due to the Balearic Islands and their associated shadow effects (see the location of the Catalan coast in Fig. 1). Locally, at the Ebre Delta (southern Catalan coast), there is a considerable presence of waves from the NW sector, due to the Mestral wind funnelled through the Ebre river valley. However, fewer extreme waves are developed near the coast as there is limited fetch.

As mentioned above, Fig. 5 illustrates the spatial $E_{\mathrm{s}}$ distribution among the different sectors along the Catalan coast. Blank squares mean a lack of storms during the entire data period (1958-2001). Note that for some locations, some combinations of node-direction (e.g. W) show calm situations without any storms. Therefore, a significant trend analysis of wave storminess cannot be carried out for such cases.

The mean storm energy oscillates between zero (indicating no storms) and $8 \mathrm{~m}^{2}$ day. Values of up to $180 \mathrm{~m}^{2}$ day are reached for the maximum variable (see Fig. 5). According to Mendoza and Jiménez (2006), these values correspond to storms classified as Moderate (II) and Extreme (V), respectively. If a simple triangular-shaped storm is assumed, Eq. (13) follows:

$$
E=H_{\mathrm{s}, \text { peak }}^{2} d / 3
$$

where $H_{\text {s,peak }}$ is the significant wave height of the storm peak and $d$ is the storm duration. Along the Catalan coast, $d$ is generally less than $24 \mathrm{~h}$ (Sánchez-Arcilla et al., 2008). If a

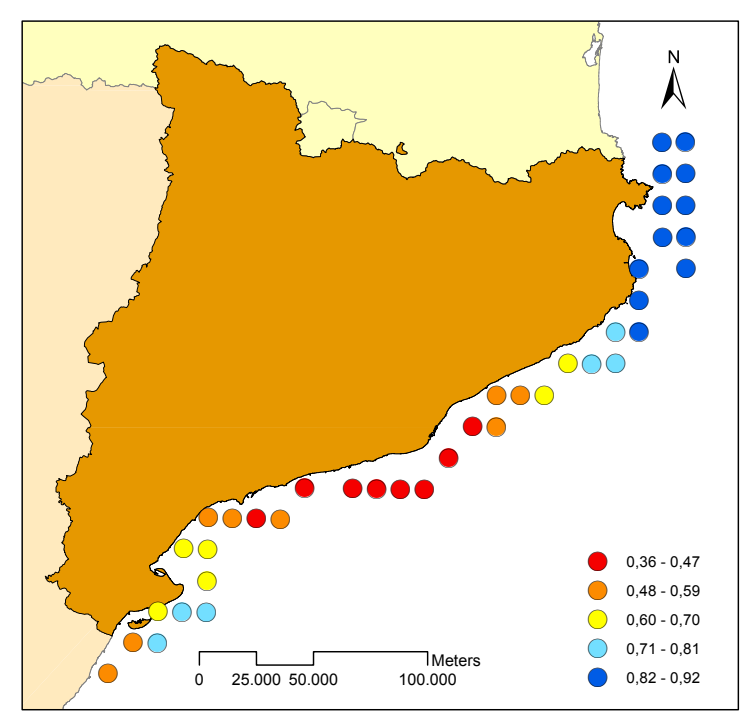

Fig. 6. Circular correlation between wind and wave direction in stormy conditions.

reasonable value of $20 \mathrm{~h}$ (similar to that found by Mösso et al., 2009) is considered and Eq. (13) is used, a mean wave storminess of $6 \mathrm{~m}^{2}$ day corresponds to $H_{\mathrm{s} \text {, peak }}=4.6 \mathrm{~m}$.

To roughly distinguish between sea and swell, the circular correlation (Fisher and Lee, 1983) between wind and wave directions is used, as illustrated in Fig. 6. As expected, it is found that northern locations (with most events coming from the $\mathrm{N}$ ) are highly correlated $(0.81-0.92)$, which can be explained by the lower $\mathrm{N}$ fetch and the greater presence of sea-type waves. Conversely, in the mid-southern part, $\mathrm{E}$ predominance is related to more mixed sea states, with poor correlations of $0.36-0.59$. The correlation is higher in the area surrounding the Ebre Delta. This could be due to the relatively high presence of locally developed waves, caused by the aforementioned Mestral (NW) winds. 


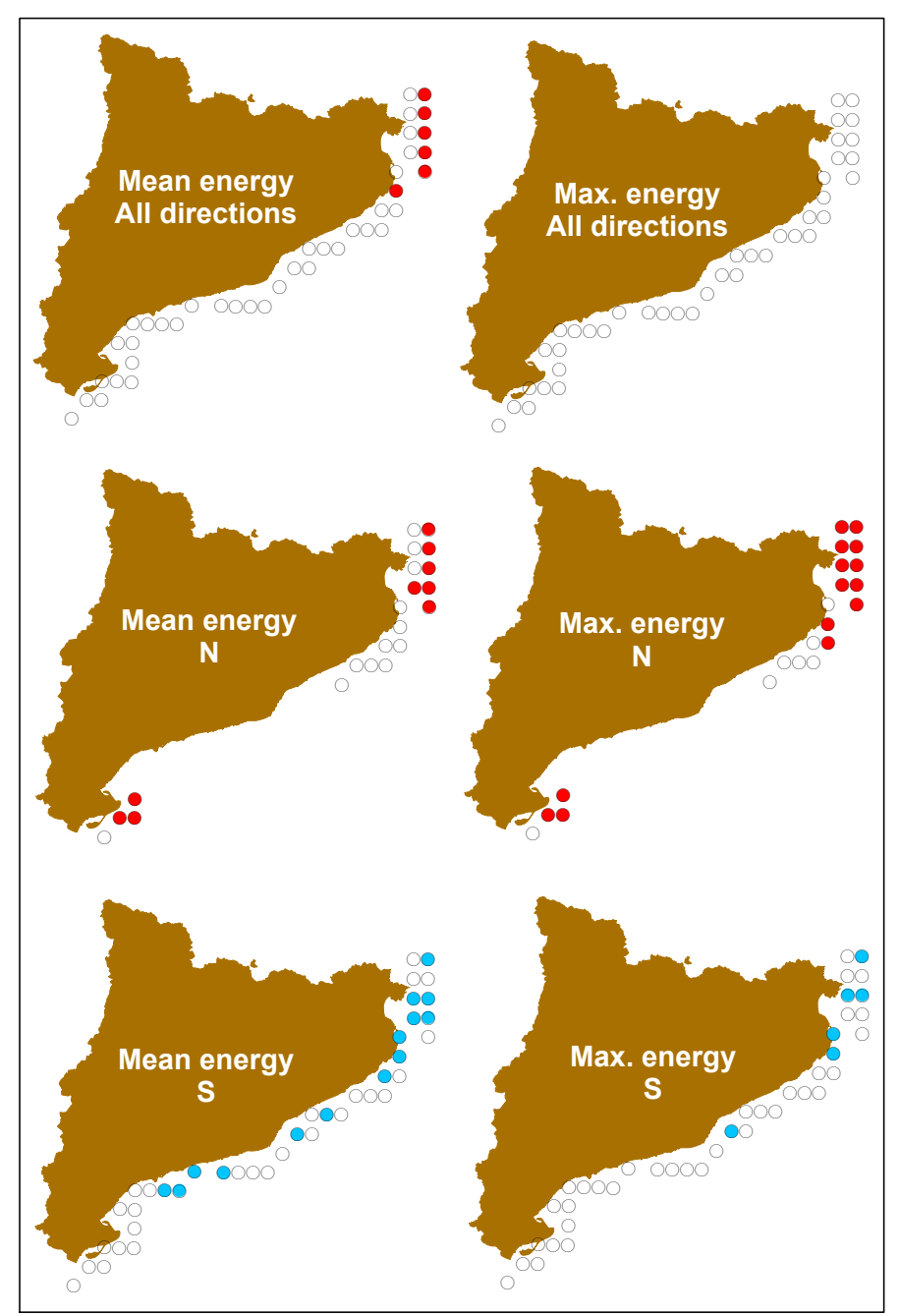

Fig. 7. Trend detection of $E_{\mathrm{S}}$ for some directions. Red: negative trend. Blank: no significant trend. Blue: positive trend (adapted from Casas-Prat and Sierra, 2010).

\subsection{Trend analysis of storm energy content}

Regarding trend quantification with the MK test, as found by Casas-Prat and Sierra (2010), the temporal trends are null or even negative (in a few offshore locations of the northern Catalan coast) when all wave directions are considered. In the northern Catalan coast, these negative trends may be partly related to the temporal evolution of events coming from the N, which tend to decrease. Figure 7 shows some of the most significant results, in which a few nodes have been deleted to better illustrate that there are no storms in these locations for such directions.

For all nodes, the trend in the $\mathrm{E}$ (most energetic) direction is not significant (not shown here). Therefore, the magnitude of the most severe storms will not tend to change. In contrast, increasing energy is expected for $\mathrm{S}$ storms, as illustrated in Fig. 7 (blue dots). This rise does not affect the entire Catalan coast but could be relevant locally. After a visual examination of the temporal evolution in $E_{\mathrm{S}}$ of $\mathrm{S}$ storms for some nodes in which trends have been detected, it is found that apart from a certain rise in magnitude, the positive trend is mostly related to an annual increase in the probability of storm occurrence. As shown in Sect. 4.3, this leads to a higher percentage of $\mathrm{S}$ storms. Figure 8 illustrates two examples (nodes 2 and 31) of this evolution in which events from the $\mathrm{S}$ are more common in the last decade than in the first one. For this direction, an annual lack of storms (zero energy) is not negligible. Therefore, as explained in Sect. 3.2, the probability of storm occurrence is incorporated. Figure 9 shows an example of the temporal trend, in which the final trend (continuous red line) can be compared with the trend of $E_{\mathrm{S}}$ when an S storm occurs (dashed red line). In addition, the 1000 bootstrapped samples of trends are plotted and the black dashed lines show the $95 \%$ confidence intervals. To compare the trends for different locations, these complex tendencies have been characterised 


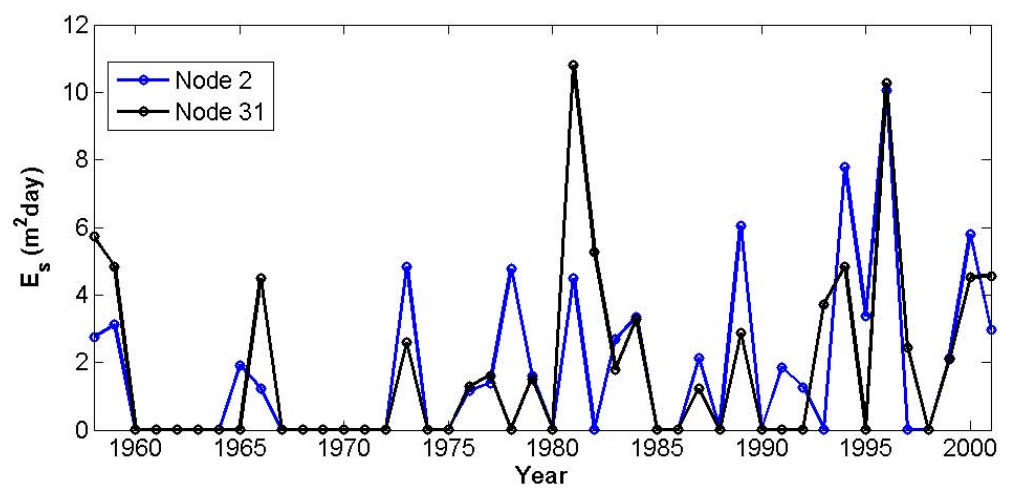

Fig. 8. Two examples of annual mean $E_{\mathrm{S}}$ temporal evolution for storm events coming from $\mathrm{S}$.

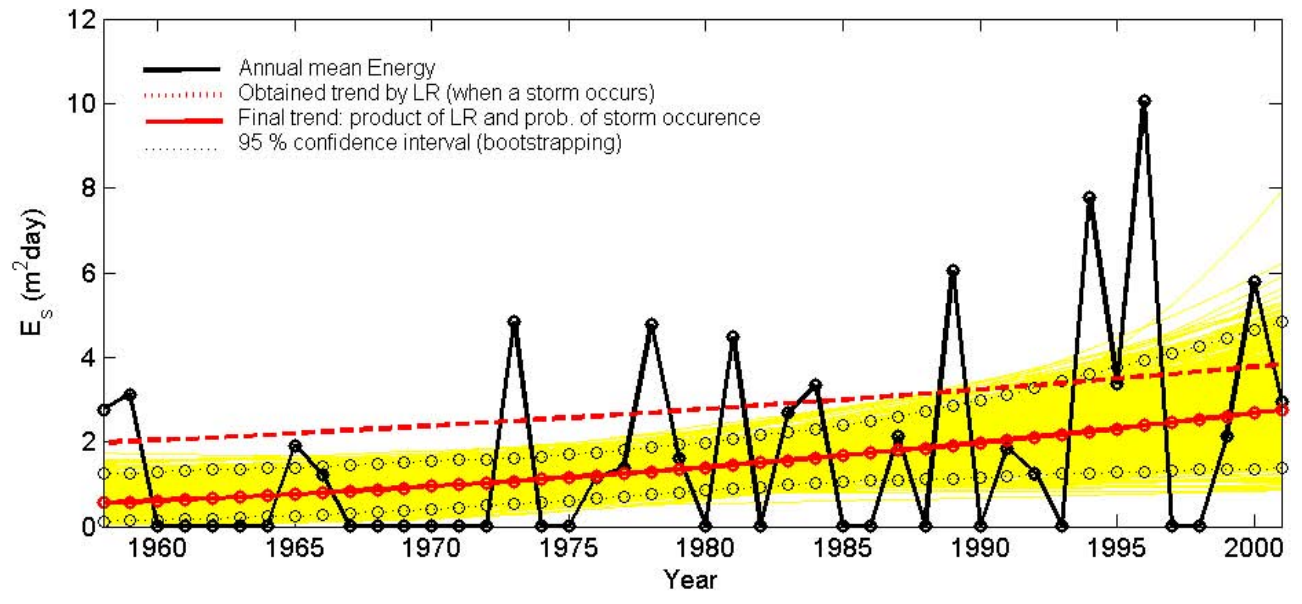

Fig. 9. An example of trend quantification of annual mean $E_{\mathrm{S}}$ from $\mathrm{S}$ (node 2, see Fig. 1). LR means linear regression.

by a single number: the mean rate of annual increase. This has been computed as the slope between $E_{\mathrm{S}}(t=1958)$ and $E_{\mathrm{S}}(t=2001)$ and is shown in Fig. 10 for S storms. Some of the nodes are marked with red dots to represent the locations in which a trend has been detected by the MK test (see Fig. 7). We can see that the majority of these nodes have most of the confidence interval within the positive area, which means that the $E_{\mathrm{s}}$ for $\mathrm{S}$ events are highly likely to increase. Moreover, the nodes with higher low confidence bounds are generally associated with the MK detection.

\subsection{Trend analysis of wave directional frequency}

Figure 11 shows the trend quantification of the $S$ directional frequency of an example (node 31) as well as an extrapolation up to 2050 . There is a considerable mean increase for this direction, but the confidence intervals cover a wide region, especially for the future prediction. This high uncertainty is due to the large inter-annual variability and the implicit reduction in data associated with the extreme analysis and the classification into sectors.
In Fig. 12, future projections for the mid-century (2050) are illustrated for all directions and compared with the 2010 projection (which represents the present situation). At locations with a considerable number of $\mathrm{N}$ events (e.g. node 2), this direction tends to decrease whereas a generalised increase in $\mathrm{S}$ frequency is detected at most locations. For example, for nodes 2 and 31, the $S$ frequency is expected to at least double, in mean terms. In addition, the most energetic direction (E) does not significantly vary, except at some locations (e.g. node 31 ) for which the annual mean frequency tends to decrease (but not the energy, see Sect. 4.2). In Fig. 12, the marginal confidence bounds are complemented with 1000 bootstrapped samples of the future prediction, to visually integrate the interaction of uncertainty between the sectors.

\subsection{Application to harbour agitation}

As mentioned above, changes in wave direction can affect the agitation pattern inside harbours. The predominant storms on the Catalan coast are from the NE and the E. As a result, 


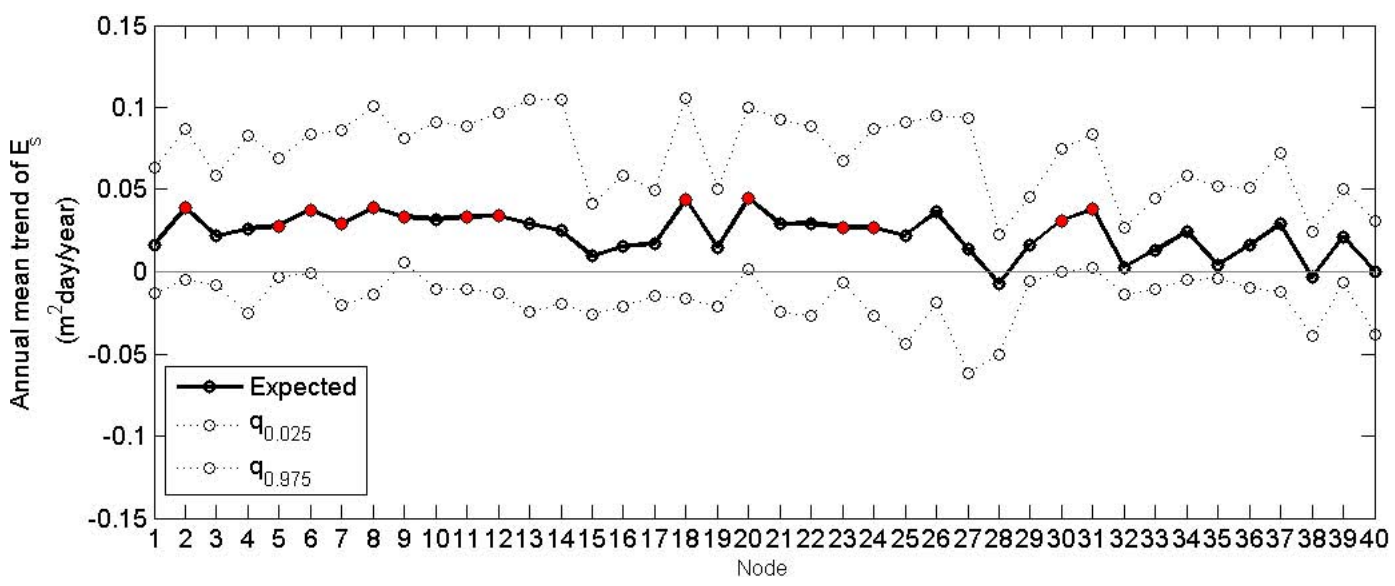

Fig. 10. Annual mean rate of increase/decrease of $E_{\mathrm{S}}$ (slope between $E_{\mathrm{S}}(t=1958)$ and $\left.E_{\mathrm{S}}(t=2001)\right)$ of storm events coming from $\mathrm{S}$ for all nodes along the Catalan coast (for the time period 1958-2001). In addition, their $95 \%$ confidence intervals are added and those nodes with detected trend by Mann-Kendall (MK) test are marked in red.

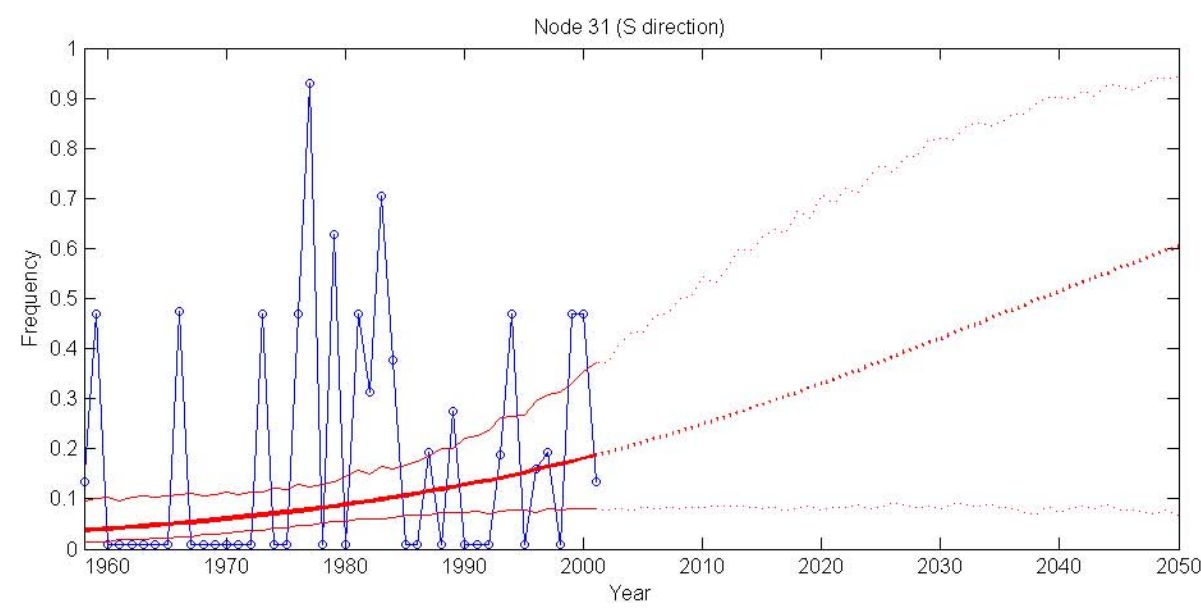

Fig. 11. Trend extrapolation of events coming from $S$ in node 31 . The figure shows the $95 \%$ confidence interval.

almost all Catalan harbours have entrances oriented towards the SW. Consequently, a rise in the number of southern wave storms could increase the waves in port berths, which would affect the safety and comfort of moored vessels. To illustrate this problem, the average agitation in the Tarragona Port (located close to node 30) was computed through a Boussinesq numerical model for the present conditions and the 2050 projections.

Figure 13 shows the plan of the Port and the surrounding coast. The existence of headlands and capes prevents the incidence of waves from the NE and SW in the Port. Therefore, only waves from the E, SE and S are considered in the analysis of agitation inside this port.

Figure 14 shows the agitation coefficient maps for the aforementioned three directions. The simulations were carried out with a peak wave period $\left(T_{\mathrm{p}}\right)$ of $10 \mathrm{~s}$ that can be considered typical for storm conditions. In fact, after performing a correlation between the mean period $\left(T_{\mathrm{m}}\right)$ and $H_{\mathrm{s}}$, we found that $T_{\mathrm{m}}=3.92 \sqrt{H_{\mathrm{s}}}$, which means that $T_{\mathrm{p}}=10 \mathrm{~s}$ corresponds to $H_{\mathrm{s}}=5 \mathrm{~m}$. The breakwater offers very good protection in the entire Port against $\mathrm{E}$ and SE waves (agitation coefficients below 0.2), although the wave penetration of SE waves is clearly higher. For S waves, the agitation coefficients increase dramatically in the entire Port, to reach values of approximately 0.4 in areas close to the port entrance. This means that high waves outside the port can affect port operations in different areas inside the harbour. The average agitation coefficients in the Port are 0.082 for E, 0.128 for SE and 0.230 for $\mathrm{S}$.

Table 1 illustrates the changes in the average agitation coefficients for the 2010 and 2050 projections. Storm direction frequencies for node 30 indicate that in year 2050 

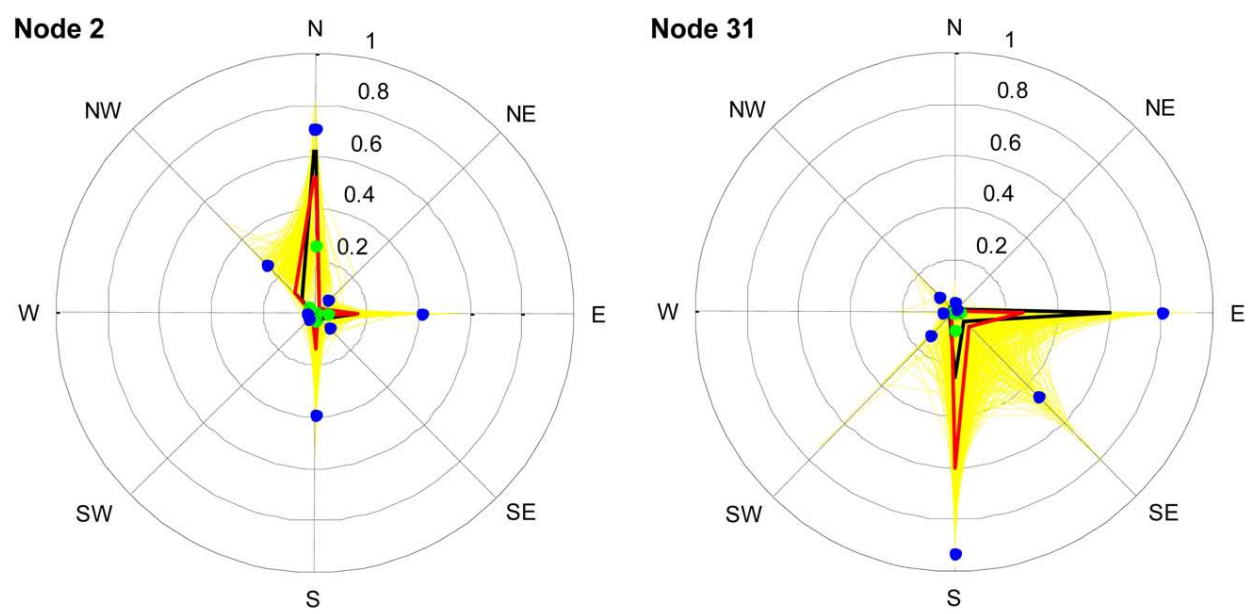

Fig. 12. Comparison between 2010 and 2050 projections (nodes 2 and 31, see Fig. 1). Black: 2010 annual mean frequency. Red: 2050 annual mean frequency. Yellow: bootstrapped 2050 projected sample. Green and blue dots: 95\% marginal confidence intervals.

Table 1. Agitation coefficients $\left(K_{\mathrm{a}}\right)$ for the studied directions, and the frequency of storm presentation $\left(\hat{p}_{i}\right)$ under projected present $(2010)$ and future (2050) conditions.

\begin{tabular}{lccccc}
\hline Direction & $K_{\mathrm{a}}$ & $\begin{array}{c}\hat{p}_{i} \\
(2010)\end{array}$ & $\begin{array}{c}\hat{p}_{i} \\
(2050)\end{array}$ & $\begin{array}{c}K_{\mathrm{a}} \cdot \hat{p}_{i} \\
(2010)\end{array}$ & $\begin{array}{c}K_{\mathrm{a}} \cdot \hat{p}_{i} \\
(2050)\end{array}$ \\
\hline $\mathrm{E}$ & 0.082 & 0.44 & 0.10 & 0.036 & 0.008 \\
$\mathrm{SE}$ & 0.128 & 0.06 & 0.05 & 0.008 & 0.006 \\
$\mathrm{~S}$ & 0.230 & 0.38 & 0.80 & 0.087 & 0.184 \\
Global average $K_{\mathrm{a}}$ & & & 0.131 & 0.198 \\
(95\% conf. intervals) & & & $(0.095,0.180)$ & $(0.102,0.227)$ \\
\hline
\end{tabular}

the number of $\mathrm{E}$ storms will significantly decrease (from $44 \%$ to $10 \%$ ), while storms from the $\mathrm{S}$ will dramatically increase (from $38 \%$ to $80 \%$ ). If we take into account the average agitation coefficients in the entire Port for the three directions, we can derive an overall average agitation coefficient. This overall coefficient has a value of 0.131 for the present conditions and 0.198 for the 2050 projections. The respective $95 \%$ confidence intervals are $(0.095,0.180)$ and $(0.102,0.227)$. This represents a mean increase of about $50 \%$ in the average agitation inside the harbour due to storm waves, which could have severe consequences on harbour functionality by affecting loading, unloading and mooring operations, reducing port efficiency and increasing the economic costs for the users.

However, the uncertainty is high and the relative difference between 2010 and 2050 may range between $-40 \%$ and $140 \%$. Therefore, the results must be handled with care, even though they illustrate the potentially severe impact on port operations of changes in wave direction under storm conditions.

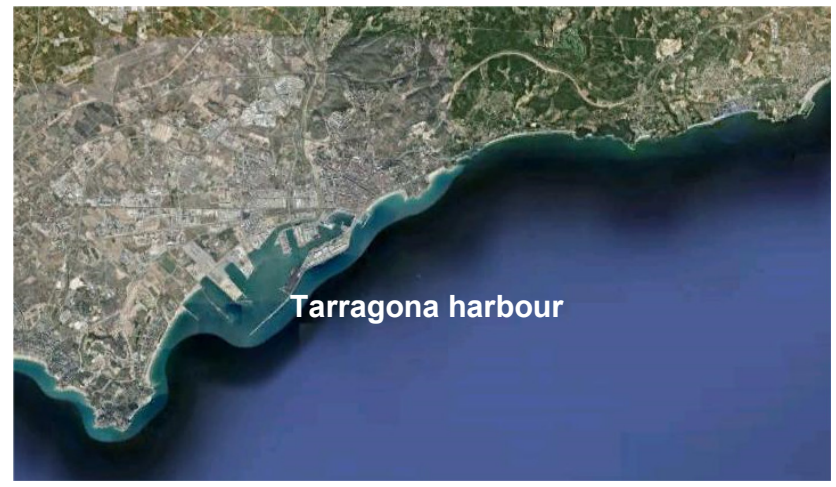

Fig. 13. Plan of the Tarragona Port and surrounding coast, showing that headlands prevent waves from NE and SW from reaching the port area. 

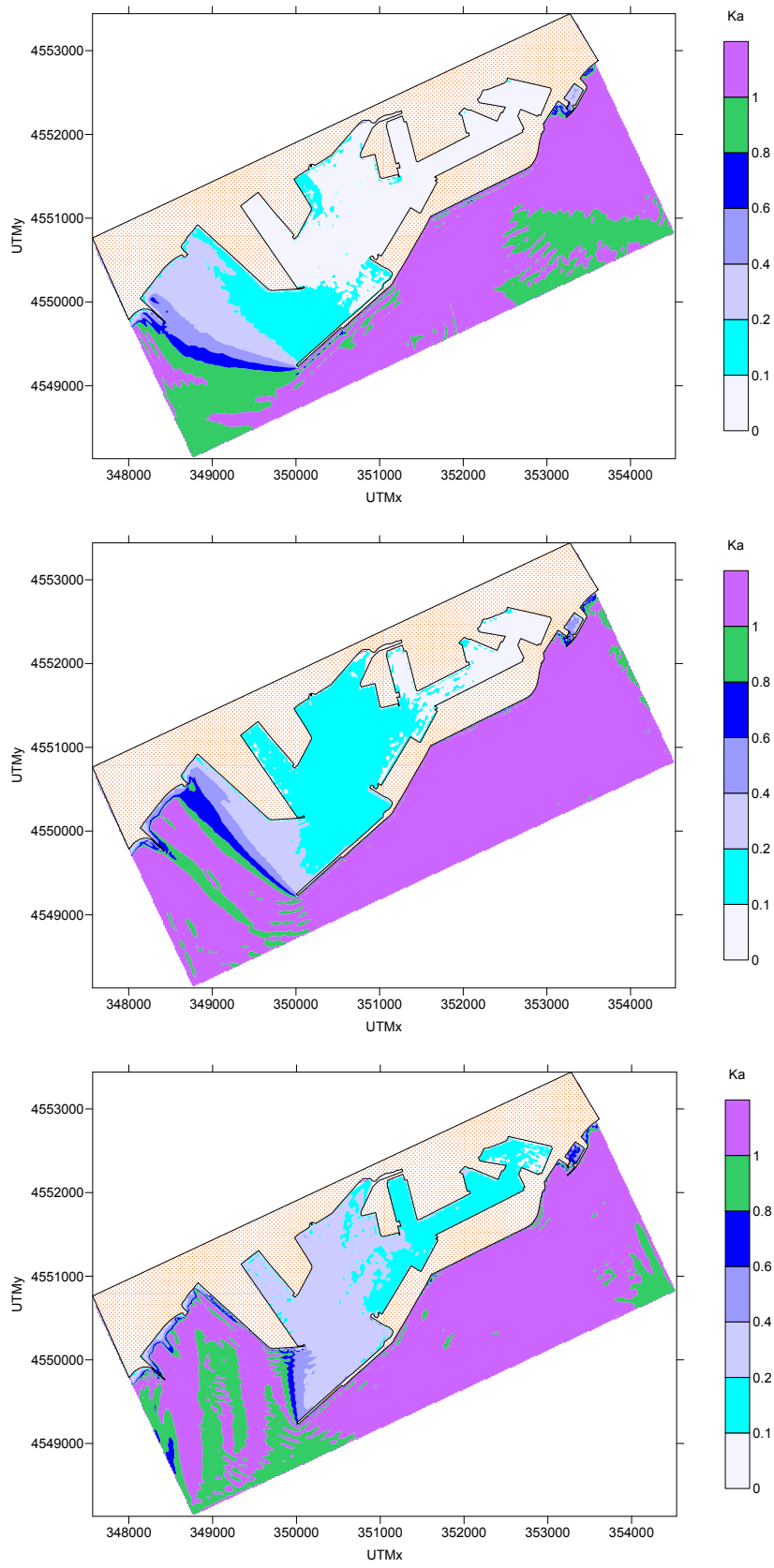

Fig. 14. Maps of agitation coefficients for E (top), SE (centre) and S (bottom) waves.

\section{Conclusions}

The Catalan coast has a variable wave climate in which both sea and swell conditions are generally present, depending on the fetch. The E direction, which is more closely related to mixed sea states, is the most frequent and energetic, with the exception of the northern part of the coast in which the $\mathrm{N}$ direction is more common (but milder than $\mathrm{E}$ ).
Regarding the trend analysis of storm energy content, which is a representative parameter of wave storminess, the temporal trend that takes into account all directions is generally null for both annual mean and maximum values. Exceptionally, some negative trends are found for locations on the northern coast, which are partly associated with a decrease in $E_{\mathrm{s}}$ from the N. The energy of $\mathrm{E}$ storms has a null trend, but a significant positive trend is obtained for $\mathrm{S}$ storms, which is related to an increase in the magnitude of storms and in the probability of their occurrence. It was useful to separate the data into different wave directions, to detect trends that are not captured in an overall analysis. However, this classification reduces the number of data items in the analysis, somewhat increases the uncertainty, and adds the difficulty of dealing with a considerable number of zeros.

The trend in annual frequencies of wave directions has been assessed and consistent trends have been found with the storm energy content. The increase in S frequency is noteworthy. However, the uncertainty is large, which makes it difficult to build robust future predictions. Therefore, the application to the case study must be taken as a situation that may occur, but with a high level of uncertainty, as is partly quantified by the $95 \%$ confidence bounds. In addition, note that the choice of temporal model for the extrapolation of future projections produces a certain inherent uncertainty in the results, which is very difficult to evaluate. However, if no convincing alternative temporal pattern is known, simple trend shapes should be used according to the parsimony principle.

As an example of the potential implications of changes in the main wave direction during storms, the agitation in Tarragona Port (one of the most important ports on the Catalan coast) has been analysed through a Boussinesqtype numerical model. The comparison between present conditions and projections for 2050 (bearing in mind the large uncertainty that exists in these projections) indicates that the average agitation inside the Port under stormy conditions could be increased in mean terms by $50 \%$. This would affect moored vessels and port operations, reduce port efficiency and increase costs for users. Therefore, the hazards of potential changes in wave direction during storms cannot be underestimated and should be taken into account in studies that analyse possible impacts of climate change.

In conclusion, the methods described above have served to evaluate the long-term tendency of wave climate parameters in stormy conditions, and to assess part of their uncertainty. These results are of course limited to the nature of the hindcast data. In addition, a relation between these possible future changes and (anthropogenic) climate change is plausible, but has not been proven. This is the "attribution" problem (Weisse and von Storch, 2010), which is very difficult to solve and should be the focus of future studies in the field. 
Acknowledgements. The research was carried out in the frame of the EU project "Climate Change and Impact Research: The Mediterranean Environment (CIRCE)" (contract number TST5CT-2007-036961) and the Spanish project "Vulnerabilidad, impactos y adaptación al cambio climático: estudio integrado sobre la agricultura, recursos hídricos y costas (ARCO)" (contract number 200800050084350). We are grateful to the Organismo Público Puertos del Estado (Spanish National Ports and Harbours Authority) for providing HIPOCAS data and to the Xarxa d'Instruments Oceanogràfics i Meteorològics de la Generalitat de Catalunya (XIOM, Catalan instrumental network) for buoy data. The first author is supported by an UPC PhD grant and the Col-legi d'Enginyers de Camins, Canals i Ports - Catalunya (Civil Engineering Association in Catalonia).

Edited by: J. Salat

Reviewed by: M. Marcos and another anonymous referee

\section{References}

Agresti, A.: Categorical data analysis, 2nd edn., Wiley, New York, USA, 734 pp., 2002.

Alvarez-Ellacuria, A., Orfila, A., Olabarrieta, M., Gómez-Pujol, L., Medina, R., and Tintoré, J.: An alert system for beach hazard management in the Balearic Islands, Coast. Manage., 37(6), 569584, doi:10.1080/08920750903150662, 2009.

Bertotti, L. and Cavaleri, L.: The predictability of the "Voyager" accident, Nat. Hazards Earth Syst. Sci., 8, 533-537, doi:10.5194/nhess-8-533-2008, 2008.

Bingham, H. B.: A hybrid Boussinesq-panel method for predicting the motion of a moored ship, Coast. Eng., 40, 21-38, doi:10.1016/S0378-3839(00)00002-8, 2000.

Casas-Prat, M. and Sierra, J. P.: Trend analysis of the wave storminess: the wave direction, Adv. Geosci., 26, 89-92, doi:10.5194/adgeo-26-89-2010, 2010.

Chen, Y. and Liu, P.L.-F.: Modified Boussinesq equations and associated parabolic models for water wave propagation, J. Fluid Mech., 288, 351-381, doi:10.1017/S0022112095001170, 1995.

De Zolt, S., Lionello, P., Nuhu, A., and Tomasin, A.: The disastrous storm of 4 November 1966 on Italy, Nat. Hazards Earth Syst. Sci., 6, 861-879, doi:10.5194/nhess-6-861-2006, 2006.

Efron, B.: Bootstrap Methods: Another Look at the Jackknife, Ann. Stat., 7(1), 1-26, doi:10.1214/aos/1176344552, 1979.

Egozcue, J. J., Pawlowsky-Glahn, V., Mateu-Figueras, G., and Barceló-Vidal, C.: Isometric logratio transformations for compositional data analysis, Math. Geol., 35(3), 279-300, doi:10.1023/A:1023818214614, 2003.

Fisher, N. and Lee, A. J.: A correlation coefficient for circular data, Biometrica, 70, 327-332, doi:10.1093/biomet/70.2.327, 1983.

Gomis, D., Ruiz, S., Sotillo, M. G., Álvarez-Fanjul, E., and Terradas, J.: Low frequency Mediterranean sea level variability: The contribution of atmospheric pressure and wind, Global Planet. Change, 63, 215-229, doi:10.1016/j.gloplacha.2008.06.005, 2008.

González-Marco, D., Sierra, J. P., Fernández de Ybarra, O., and Sánchez-Arcilla, A.: Implications of long waves in harbor management: The Gijon port case study, Ocean Coast. Manage., 51, 180-201, doi:10.1016/j.ocecoaman.2007.04.001, 2008.
Guedes Soares, C., Carretero Albiach, J. C., Weisse, R., and Alvarez-Fanjul, E.: A 40 years hindcast of wind, sea level and waves in European waters, Proceedings of the 21st International Conference on Offshore Mechanics and Arctic Engineering, Oslo, Norway, 669-675, 2002.

Karambas, T. W. and Koutitas, C.: Resonant response of harbours to short-wave group, Maritime Engineering, 157, 163-170, doi:10.1680/maen.2004.157.4.163, 2004.

Kendall, M. G.: Rank Correlation Methods, Griffin, London, 1975.

Liste, M., Méndez, J., Losada, I., Medina, R., and Olabarrieta, M.: Variaciones hiperanuales de parámetros medios de oleaje en el litoral mediterráneo español en los últimos cinquenta años: efectos sobre la costa, IV Congreso de la Asociación Española de Climatología (AEC), 2004 (in Spanish).

Madsen, P. A., Murray, R., and Sørensen, O. R.: A new form of the Boussinesq equations with improved linear dispersion characteristics, Coast. Eng., 15, 371-388, doi:10.1016/03783839(91)90017-B, 1991.

Mann, H. B.: Nonparametric test against trend, Econometrica, 13, 245-259, 1945.

Marcos, M. and Tsimplis, M.: Coastal sea level trends in Southern Europe, Geophys. J. Int., 175, 70-82, doi:10.1111/j.1365246X.2008.03892.x, 2008.

Martín-Fernández, J. A., Barceló-Vidal, C., and Pawlowsky-Glahn V.: Dealing with zeros and missing values in compositional data sets using nonparametric imputation, Math. Geol., 35(3), 253278, doi:10.1023/A:1023866030544, 2003.

Mendoza, E. T. and Jiménez, J. A.: Factors controlling vulnerability to storm impacts along the Catalonian coast, in: Proceedings of the 29th International Conference on Coastal Engineering Lisbon, Portugal, 3087-3099, 2004.

Mendoza, E. T. and Jiménez, J. A.: Storm-induced beach erosion potential on the Catalonian coast, J. Coast. Res., Special Issue 48, 81-88, 2006.

Mestres, M., Sierra, J. P., Mösso, M., and Sánchez-Arcilla, A.: Sources of contamination and modelled pollutant trajectories in a Mediterranean harbour (Tarragona, Spain), Mar. Pollut. Bull., 60, 898-907, doi:10.1016/j.marpolbul.2010.01.002, 2010.

Monbaliu, J., Padilla Hernández, R., Hargreaves, J., Carretero, J. C., Weimin, L., Sclavo, M., and Gunther, H.: The spectral wave model, WAM adapted for applications with high spatial resolution, Coast. Eng., 41, 41-62, doi:10.1016/S03783839(00)00026-0, 2000.

Mösso, C., Mestres, M., Sierra, J. P., Sánchez-Arcilla, A., and Goodess, C.: Waves and surges in the Valencia Gulf. Variability rather than climate change, J. Coast. Res., Special Issue 56, $243-$ 247, 2009.

Musić, S. and Nicković, S.: 44-year wave hindcast for the Eastern Mediterranean, Coast. Eng., 55, 872-880, doi:10.1016/j.coastaleng.2008.02.024, 2008.

Nadaoka, K. and Raveenthiran, K.: A phase-averaged Boussinesq model with effective description of carrier wave group and associated long wave evolution, Ocean Eng., 29, 21-37, doi:10.1016/S0029-8018(01)00024-5, 2002.

Nwogu, O.: An alternative form of the Boussinesq equations for nearshore wave propagation, J. Waterway Port C. Div., 119, 618-38, doi:10.1061/(ASCE)0733-950X(1993)119:6(618)), 1993. 
Pawlowsky-Glahn, V. and Egozcue, J. J.: Compositional data and their analysis: an introduction (in compositional data analysis in the geosciences; from theory to practice), Geological Society, London, Special Publications, 264, 1-10, doi: 10.1144/GSL.SP.2006.264.01.01,, 2006.

Peregrine, D. H.: Long waves on a beach, J. Fluid Mech., 27, 815882, doi:10.1017/S0022112067002605, 1967.

Ratsimandresy, A. W., Sotillo, M. G., Álvarez Fanjul, E., Carretero Albiach, J. C., Pérez Gómez, B., and Hajji, H.: A 44-year (19582001) sea level residual hindcast over the Mediterranean Basin, Phys. Chem. Earth, 33, 250-259, doi:10.1016/j.pce.2007.02.002, 2008a.

Ratsimandresy, A. W., Sotillo, M. G., Carretero Albiach, J. C., Álvarez Fanjul, E., and Haiji, H.: A 44-year high resolution ocean and atmospheric hindcast for the Mediterranean Basin developed within the HIPOCAS project, Coast. Eng., 55, 827842, doi:10.1016/j.coastaleng.2008.02.025, 2008 b.

Sánchez-Arcilla, A., González-Marco, D., and Bolaños, R.: A review of wave climate and prediction along the Spanish Mediterranean coast, Nat. Hazards Earth Syst. Sci., 8, 12171228, doi:10.5194/nhess-8-1217-2008, 2008.

Sierra, J. P., Sánchez-Arcilla, A., Egozcue, J. J., and Monsó, J. L.: Effect of Boussinesq-type equations on wave spectra propagation. Proceedings of the 21st International Conference on Coastal Engineering, Málaga, Spain, 350-362, 1988.

Soomere, T., Behrens, A., Tuomi, L., and Nielsen, J. W.: Wave conditions in the Baltic Proper and in the Gulf of Finland during windstorm Gudrun, Nat. Hazards Earth Syst. Sci., 8, 37-46, doi:10.5194/nhess-8-37-2008, 2008.

Sotillo, M. G., Ratsimandresy, A. W., Carretero, J. C., Bentamy, A., Valero, F., and González-Rouco, F.: A high-resolution 44-year atmospheric hindcast for the Mediterranean Basin: contribution to the regional improvement of global reanalysis, Clim. Dynam., 25, 219-236, doi:10.1007/s00382-005-0030-7, 2005.
Tomás, A., Méndez, F. J., Medina, R., Losada, I. J., Menéndez, M., and Liste, M.: Bases de datos de oleaje y nivel del mar, calibración y análisis: el cambio climático en la dinámica marina en España, IV Congreso de la Asociación Española de Climatología (AEC), 2004 (in Spanish).

Tsimplis, M., Marcos, M., Somot, S., and Barnier, B.: Sea level forcing in the Mediterranean between 1960 and 2000, Global Planet. Change, 63, 325-332, doi:10.1016/j.gloplacha.2008.07.004, 2008.

van Gelder, P. H. A. J. M., Mai, C. V., Wang, W., Shams, G., Rajabalinejad, M., and Burgmeijer, M.: Data management of extreme marine and coastal hydro-meteorological events, J. Hydraul. Res., 46(Extra Issue 2), 191-210, doi:10.1080/00221686.2008.9521954, 2008.

von Storch, H.: Misuses of Statistical Analysis in Climate Research, in: Analysis of Climate Variability: Applications of Statistical Techniques, edited by: Storch, H. V. and Navarra, A., Springer, New York,11-26, 1995.

WAMDI Group: Hasselman, S., Hasselman, K., Janssen, P. A. E. M., Komen, G. J., Bertotti, L., Lionello, P., Guillaume, A., Cardone, V. C., Greenwood, J. A., Reistad, M., Zambresky, L., and Ewing, J. A.: The WAM model - A third generation ocean wave prediction model, J. Phys. Oceanogr., 18, 17751810, 1988.

Weisse, R. and von Storch, H.: Marine Climate and Climate Change, in: Storms, Wind Waves and Storm Surges, Springer, Praxis Publishing, Chichester, UK, 2010.

Woo, S.-B. and Liu, P. L.-F.: Finite-element model for modified Boussinesq equations. II: Applications to nonlinear harbour oscillations, J. Waterway. Port C. Div., 130(1), 17-28, doi:10.1061/(ASCE)0733-950X(2004)130:1(17), 2004. 